\title{
Meta-analysis of Prevalence of Cronobacter sakazakii in Foods Consumed in Turkey
}

\author{
Serhat AL ${ }^{*}$, Adalet DIŞHAN 1 , Elif ÇELİK², Aytaç AKÇAY² \\ ${ }^{1}$ Erciyes University, Faculty of Veterinary Medicine, Food Hygiene and Technology Department, Kayseri, Turkey \\ ${ }^{2}$ Erciyes University, Faculty of Veterinary Medicine, Biometry Department, Kayseri, Turkey
}

\begin{abstract}
In this study, it is aimed to make meta-analysis of the prevalence of Cronobacter sakazakii in various foods consumed in Turkey. The prevalences of $C$. sakazakii detected in the different independent studies were combined to provide a common prevalence estimate and heterogeneities between studies were investigated. The study material consisted of 22 studies investigating C. sakazakii prevalence in a total of 2463 food samples included infant formula, infant formula ingredients, milk and dairy products and meat and meat products between the years 1997-2019 was carried out in Turkey. As a result of the meta-analysis, the common prevalence of $C$. sakazakii was detected as (\%95 Confidence Interval; 0.021-0.044) for all studies. In the evaluated studies, infant formula, infant formula ingredients, milk and dairy products and meat and meat products were identified as subgroups due to sufficient prevalence data and meta-regression analysis was applied between sub-groups. Accordingly, the prevalence of $C$. sakazakii in infant formula, infant formula ingredients, milk and dairy products and meat and meat products were determined as 0.01 (0.00-0.01), $0.11(0.04-0.18), 0.05(0.02-0.08)$ and $0.03(0.00-$ 0.06) in Turkey, respectively. Heterogeneities due to sampling size of studies on the presence of C. sakazakii in foods consumed in Turkey were corrected and main prevalence of the pathogen in Turkey is calculated. The study concluded that the pathogen is epidemiologically important and effective implementation of food safety management systems in the food production chain is necessary for public health.
\end{abstract}

Keywords: Cronobacter sakazakii, meta-analysis, prevalence

\section{Türkiye'de Tüketime Sunulan Gıdalarda Cronobacter sakazakii Prevalansların Meta-analiz ile} Belirlenmesi

\section{ÖZ}

Bu çalışmada, Türkiye'de tüketime sunulan çeșitli gıdalarda tespit edilen Cronobacter sakazakii prevalanslarının meta-analizinin yapılması amaçlanmıştır. Birbirinden bağımsız olarak yapılmış çalışmalarda belirlenen C. sakazakii prevalansları birleştirilerek Türkiye için ortak prevalans kestirimi sağlanmış ve çalışmalar arası heterojenlikler araştırılmıştır. Çalışma materyalini, 2008-2019 yılları arasında Türkiye'de yapılmış C. sakaz̧akii prevalansının belirlendiği 22 adet çalışma ve bu çalışmalarda incelenen 2463 gida numunesi oluşturmuştur. Meta-analiz sonucunda C. sakazakii ortak prevalans değeri 0.033 (\%95 Güven aralığ1; 0.021-0.044) olarak bulunmuştur. İncelenen çalışmalarda bebek maması, bebek maması yapımında kullanılan hammaddeler, süt ve süt ürünleri ve et ve et ürünleri, yeterli prevalans verisi bulunduğundan alt gruplar olarak belirlenmiş ve alt gruplar arası metaregresyon analizi uygulanmıştır. Çalışma bulgularına göre Türkiye'de C. sakaz̧akii prevalansı; bebek maması, bebek mamas1 hammaddeleri, süt ve süt ürünleri ve et ve et ürünlerinde sirasiyla 0.01 (0.00-0.01), 0.11 (0.04-0.18), 0.05 $(0.02-0.08)$ ve $0.03(0.00-0.06)$ olarak ortaya konulmuştur. Türkiye'de tüketime sunulan gidalarda C. sakazakii varlığına ilişkin yapılan çalışmaların örneklem büyüklügüne bağlı olarak göstermiş oldukları heterojeniteler giderilmiş ve patojenin Türkiye geneli ortak prevalansı hesaplanmıştır. Çalışma sonucunda etkenin epidemiyolojik olarak önemli olduğu ve üretim zincirinde gıda güvenliği yönetim sistemlerinin etkin olarak uygulanmasının halk sağlığı açısından gerekli olduğu sonucuna varılmıştır.

Anahtar Kelimeler: Cronobacter sakazakii, meta-analiz, prevalans

To cite this article: Al S. Dişhan A. Celike E. Akçay A. Meta-analysis of Prevalence of Cronobacter sakazakii in Foods Consumed in Turkey. Kocatepe Vet J. (2020) 13(1):69-76. 


\section{GİRİŞ}

Cronobacter sakazakii; gram-negatif, sporsuz, peritrik flagellaları ile hareketli, çubuk şekilli, fakültatif anaerobik özellikte, Enterobacteriaceae familyasina mensup olan gida kaynaklı bir patojendir (Kucerova ve ark. 2010, Li ve ark. 2014, Hu ve ark. 2018). İlk olarak Enterobacter sakazakii olarak isimlendirilen etken, Iversen ve ark. (2008) tarafindan C. sakazakii olarak yeniden sinıflanmıştır. Cronobacter spp.'nin $C$. sakazakii, C. turicensis, $C$. universalis, C. dublinensis, $C$. malonaticus ve $C$. muytjensii olmak üzere altı türünün g1da kaynaklı patojenler olduğu farklı çalışmalarda bildirilmektedir (Li ve ark. 2014, Garbowska ve ark. 2015, Hu ve ark. 2018). Bu altı tür, stres tolerans1 ve virülans özellikleri bakımından birbirlerinden farklıdır. Cronobacter türleri çeşitli g1da ve çevresel örneklerden izole edilen firsatçı patojenler olup enfeksiyonları başta yenidoğanlarda, çocuklarda ve yaşlilarda olmak üzere tüm yaş gruplarında rastlanmaktadır. (CDC 2011, Aksu ve ark. 2019). C. sakazakii, intestinal duvar ve kan-beyin bariyerinden geçiş yapabilme kabiliyetinde, hücresel dejenerasyon şekillendiren endotoksin üretmektedir (Holy ve Forstythe 2014). Nekrotizan enterokolit, septisemi ve menenjit şekillenebilen enfeksiyon tablolarında, bebeklerde mortalitenin \%40'a yakın olduğu rapor edilmektedir (Holy ve Forstythe 2014). Infant ve bebeklerde görülen enfeksiyonların \%90'dan fazlası epidemiyolojik olarak toz bebek formülleri ile ilişkilendirilmektedir (Li ve ark. 2014, Kalyantanda ve ark. 2015). C. sakazakii, yenidoğanlar için kontamine toz bebek formülleri ve devam mamaları ile ilişkilendirilse de tahıllar, baharatlar, ekmek, et ve et ürünleri, peynir gibi süt ürünleri, yumurta ve sebze ve meyveler gibi çeşitli g1dalarda da bulunduğu bildirilmektedir (Friederman ve ark. 2007). C. sakazakii, $\quad 6-45^{\circ} \mathrm{C}$ arasinda üreyebilmesi, 1siya, ultraviyole 1şı̆̆a, radyasyona, oksijen radikallerine, mide asitliğine dirençli olması, dehidre ve su aktivitesi düşük toz bebek mamalarında 2 yıla kadar canlılı̆̆ını koruyabilmesi gibi nedenlerle büyük bir tehlike oluşturmaktadır (Iversen ve ark. 2004, Kalyantanda ve ark. 2015). Bununla birlikte, kötü hijyenik koşullar ve kontamine alet ve ekipmanlar, besin bileşenlerinin bu bakteri ile kontamine olmasına yol açmaktadır (Jaradat ve ark. 2014).

Pek çok ülkede infant formülleri için mikrobiyolojik kriterlerde C. sakazakii sifir tolerans olarak kabul edilmektedir (Codex 2008, EC 2007, FSANZ 2016). Türk Gida Kodeksi Mikrobiyolojik Kriterler Tebliği'ne göre ise bebek formülleri ve devam formüllerinde (özel tıbbi amaçlı diyet g1dalar dahil) 25 g numunede C. sakazakii bulunmaması gerektiği belirtilmektedir (TGK 2011). C. sakazakii prevalansına ilişkin yapılmış birçok çalışma bulunmaktadır. Bu prevalansların değişkenliği daha kesin sonuçların elde edilmesi ihtiyacını doğurmuştur. Bu ihtiyaca çözüm olabilecek yöntemlerden biri meta- analiz yöntemidir. Meta-analiz, birbirinden bağımsız çalışmalardan elde edilen etki büyüklüklerinin uygun model altında birleştirilerek ortak etki büyüklüğü elde edilmesi yöntemidir. Meta-analiz ile örneklem genişliği arttırılarak kesinliği ve gücü daha yüksek olan parametreler elde edilebilmektedir. Bu sebeple, metaanaliz çalışmaları giderek önem kazanmaktadır (Sutton ve ark. 2001). Bu çalışmada, Türkiye'de 20082019 y1lları arasında gerçekleştirilmiş, tüketime sunulan çeşitli gidalarda C. sakazakii prevalansının belirlendiği çalışmalar göz önünde bulundurularak Türkiye'de ortak C. sakazakii prevalansinin metaanaliz ile belirlenmesi amaçlanmıştır.

\section{GEREÇ ve YÖNTEM}

Çalışma materyalini 2008-2019 yılları arasında Türkiye'de yapılmış gidalarda C. sakazakii prevalansını hesaplandığı 22 adet çalışmadan elde edilen 36 prevalans bulgusu oluşturmuştur. Çalışmaların analize dahil etme kriterlerini gösteren akış şeması Şekil 1'de verilmiştir. Meta-analizine bebek mamaları, bebek maması hammaddeleri, süt ve süt ürünleri, kırmız1 et ve et ürünleri ve diğer gidalardan alınan toplam 2463 g1da numunesi dahil edilmiştir

Türkiye'de C. sakazakii prevalansı ile ilgili yapılmış olan ve meta-analizine dahil edilen çalışmalara ilişkin bilgiler ise Tablo 1'de verilmiştir.

Meta-analizine dahil edilen çalışmaların çalışma etki büyüklüklerinin ve standart hataların doğrusal olup olmadı̆̆ını belirlemek için Egger'in Doğrusal Regresyon testi kullanılmıştır. Yayın yanlılığının giderilmesi için Duval ve Tweedie (2000)'nin Trim and Fill yöntemi uygulanarak ortak prevalans değeri tekrar hesaplanmıştır. Çalışma içi varyansın yanı sıra çalışmalar arasındaki varyansı tespit etmek amacıyla rastgele etki modeli (DerSimonian-Laird yöntemi) kullanılmıştır. Çalışmaların etki büyüklüklerine ait heterojenliğin değerlendirilmesinde (k-1) serbestlik dereceli Cochrane's Q istatistiği, heterojenlik seviyesini belirlemek için $I^{2}$ istatistiği ve çalışmalar arasındaki gerçek varyansın tespiti için $\tau^{2}$ istatistiğ 1 kullanılmıştır. $I^{2}$ değeri, Patsopoulos ve ark. tarafindan (2008) önerilen üç kategori (\%25'in altında ise düşük, $\% 25-50$ aras1 orta, \%50'nin üzeri yüksek heterojenlik) kullanılarak değerlendirilmiştir.

Çalışmada gıda türlerine göre (bebek mamaları, bebek maması hammaddeleri, süt ve süt ürünleri ve kırmızı et ve et ürünleri) oluşturulan alt gruplar arasında heterojenlik ölçümü yapılarak, ortak etki büyüklükleri bakımından karşılaştırmalar yapılmıştır. Metaregresyon analizinde, bağımlı değişken etki büyüklüğü (C. sakazakii prevalansı) olup, bağımsız değişken (gida türleri) ile arasındaki ilişki belirlenerek modellenmiştir. Meta-regresyon analizi sonucunda elde edilen belirtme katsayısı $\left(\mathrm{R}^{2}\right)$ istatistiğ i ile gerçek etkilerdeki varyansın ne kadarının bağımsız değişken tarafindan 
açıklandığı hesaplanmıştır. Çalışma kapsamında analizler $\mathrm{R}$ 3.6.1 (www.r-project.org) kullanılarak yapılmıştır.

\section{BULGULAR}

Yapılan meta-analiz sonucunda Türkiye'de satışa sunulan gidalarda C. sakaqakii ortak prevalans değeri 0.033 (\%95 Güven aralığ1; 0.021-0.044) olarak hesaplanmış olup istatistiksel olarak anlamlı olduğu ortaya konmuştur $(p<0.001)$. Egger'in Doğrusal Regresyon testi sonucunda çalışma örnekleminin yanlı olduğu belirlenmiştir (t-değeri: 7.47, p<0.001). Metaanaliz sonucunda çalışmalar arasında heterojenlik bulunmuştur ve gözlenen etkilerdeki varyans gerçek etkilerdeki varyansin \%71'ni vermektedir (Cochrane's $\left.\mathrm{Q}=120.76, \mathrm{df}=35, I^{2}=71\right) . \mathrm{Bu}$ nedenle rastgele etki modeli kullanılmıştır. Burada Cochrane’s Q istatistiği gözlenen etki büyüklüklerinin ağırlıklı kareler toplamını göstermektedir. Çalışmada elde edilen huni grafiği Şekil 2'de gösterilmektedir.

Çalışmalar kapsamında uygulanan Trim and Fill yönteminde yayın yanlılı̆̆ının giderilmesi için analize 14 ayrı prevalans değeri eklenmiştir. Bunun sonucunda ortak prevalans 0,012 (\%95 Güven aralığ1; 0.00-0.025) ve Cochrane's Q istatistiği ise 228.94 olarak düzeltilmiştir.

Alt grup analizlerinde bebek mamaları, bebek maması hammaddeleri, süt ve süt ürünleri ve kırmızı et ve et ürünleri için ortak prevalans değerleri hesaplanmış; gıda türleri arasındaki ilişkileri belirlemek için ise meta-regresyon analizi yapılmıştır. Tablo 2'de gıda türlerine göre yapılan altgrup analizlerinde ortak prevalans ve güven aralıkları, Cochrane's $Q, I^{2}$ ve $\tau^{2}$ test istatistikleri verilmiştir. Altgrup analizi sonucunda g1da türlerine göre $C$. sakazakii prevalansinin değişiklik gösterdiği ve g1da türlerinin ortak prevalans üzerinde anlamlı bir etkisinin bulunduğu görülmüştür $(\mathrm{Q}=17.21, \mathrm{df}=3, \mathrm{p}<0.001)$. Buna göre, en düşük $C$. sakazakii prevalans1 (0.005 (CI: 0.00-0.01), Q=9.92, $\left.\mathrm{df}=11, I^{2}: 0.0\right)$ bebek mamalarında bulunurken, en yüksek prevalans değeri ise bebek maması yapımında kullanilan hammaddelerde (0.11 (CI: 0.04-0.18), Q= 13.81, $\mathrm{df}=4, I^{2}$ : 71) olduğu belirlenmiştir. Gida tiplerine göre belirlenmiş olan alt gruplarda $C$. sakazakii prevalans değerleri Şekil 3'de detaylı olarak gösterilmiştir.

Meta-regresyon analizine göre C. sakazakii prevalans1 g1da türlerine göre değişmektedir $(\mathrm{p}<0.05)$ (Tablo 3). Bebek maması yapıminda kullanılan hammaddelerde ve süt ve süt ürünlerinde bebek mamalarına göre daha yüksek C. sakazakii riski hesaplanmış ve istatistiksel olarak anlamlı bulunmuştur $(\mathrm{p}<0.05)$. Fakat, kırmızı et ve et ürünlerinin $C$. sakazakii prevalansı üzerindeki etkisi anlamlı bulunmamıştır ( $\mathrm{p}>0.05)$. Regresyon modeline göre gerçek etkilerdeki varyansin \%47'si g1da türleri tarafindan açılanmaktadır $\quad\left(\mathrm{R}^{2}\right.$ Analog=0,47). Marul, çilek, kırmızı biber, baharatlar, karides, şekerleme, hazır toz çorba ve meyve ve sebzeler gibi gida matrislerinde belirlenen C. sakazakii prevalans verileri söz konusu etkenin genel prevalansinın belirlenmesinde göz önünde bulundurulmuş ancak yeterli sayıda çalışma olmadığ1 için alt grup ve meta-regresyon analizlerinde kapsam dişı birakılmıştır.

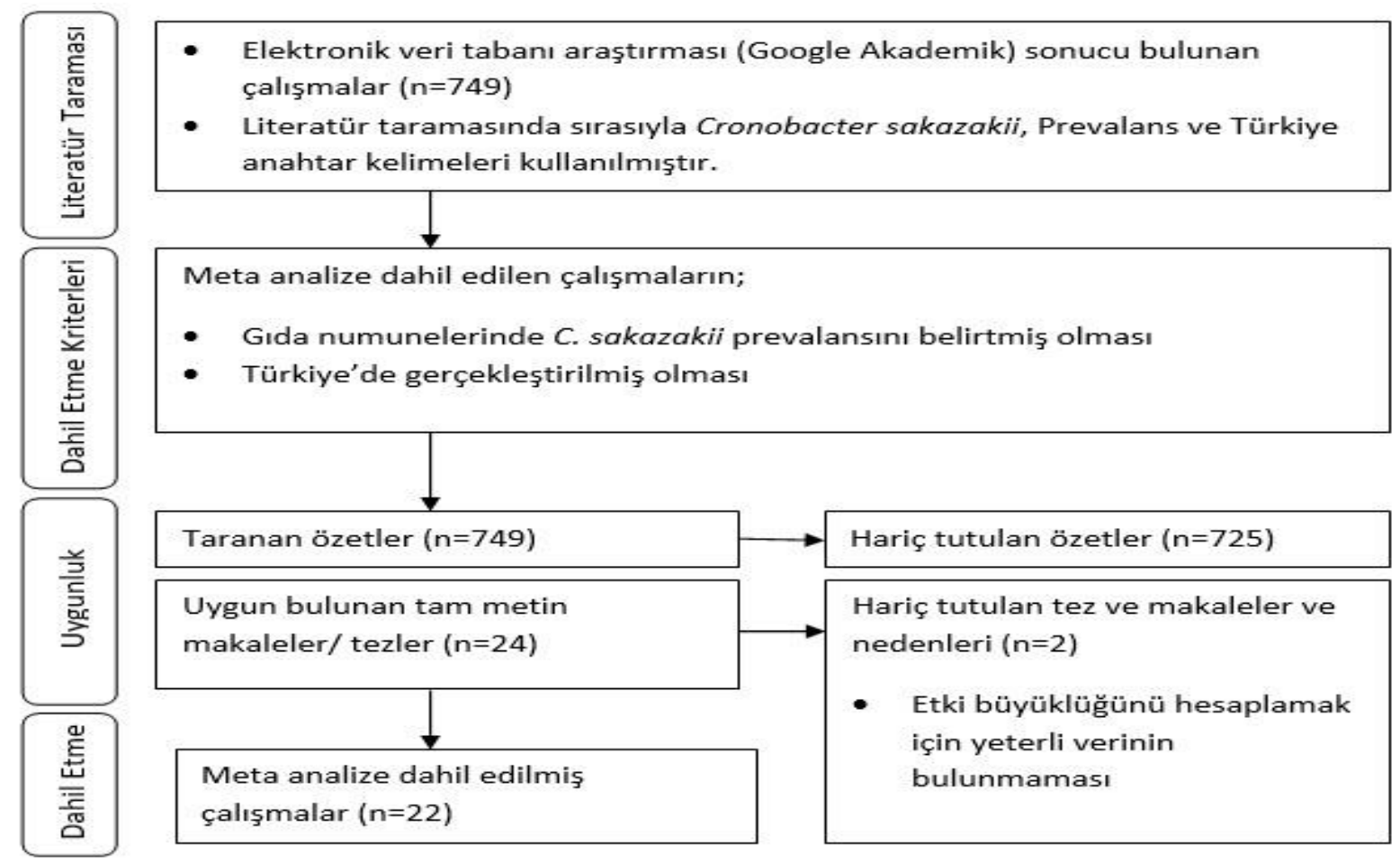

Şekil 1. Çalışmaların Meta-analize dahil etme kriterleri ile ilgili akış şeması

Figure 1. Flow diagram of the criteria for selection of studies in the meta-analysis 


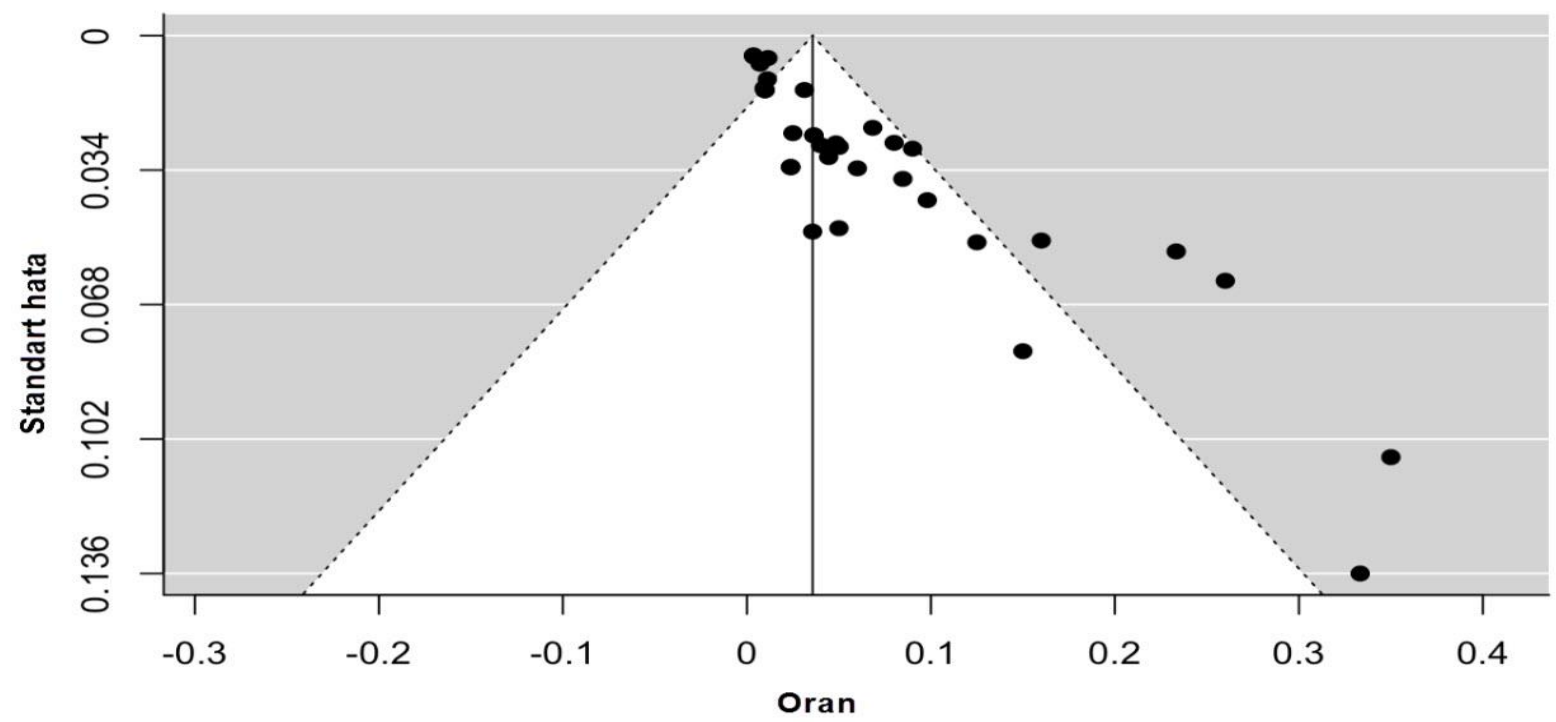

Şekil 2. 2008-2019 yılları arasında yayınlanmış C. sakąakii prevalans çalışmaları örneklemlerine ait huni grafiği $(\mathrm{n}=22)$

Figure 2. Funnel plot for estimates in meta-analysis of $C$. sakazakii prevalence studies published from 2008 to $2019(\mathrm{n}=22)$

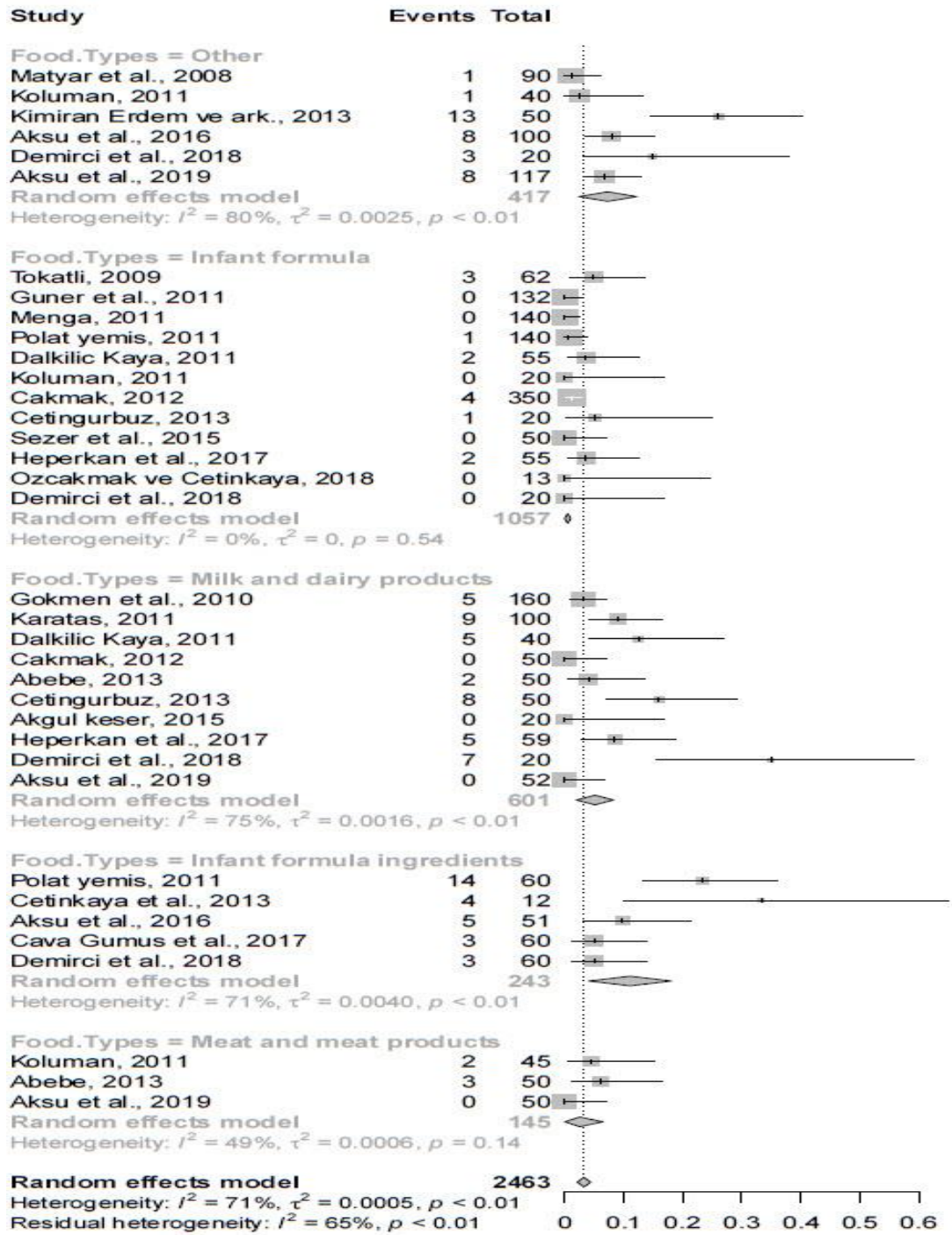

Proportion $\quad 95 \%-\mathrm{Cl}$ Weight

0.01 [0.00; 0.06] $5.1 \%$

0.02 [0.00; 0.13 ] $2.9 \%$

$0.26[0.15 ; 0.40] \quad 0.8 \%$

$0.08[0.04 ; 0.15] \quad 2.6 \%$

$0.15[0.03,0.38] \quad 0.5 \%$

$0.07[0.03: 0.13] \quad 3.1 \%$

0.05 [0.01: 0.13$] \quad 2.6 \%$

0.00 [0.00; 0.03 ] $6.0 \%$

0.00 [0.00;0.03] $6.0 \%$

0.01 [0.00; 0.04$] \quad 5.7 \%$

0.04 [0.00; 0.13$] \quad 2.9 \%$

0.00 [0.00; 0.17 ] $2.1 \%$

0.01 [0.00; 0.03$] \quad 5.9 \%$

$\begin{array}{ll}0.05 & {[0.00 ; 0.25]} \\ 0.00 & 1.2 \%\end{array}$

$\begin{array}{lll}0.00 & {[0.00 ; 0.07]} & 4.6 \% \\ 0.04 & 0.00 ; 0.13] & 2.9 \%\end{array}$

$\begin{array}{lll}0.04 & 0.00 ; 0.13] & 2.9 \% \\ 0.00 & 0.00 ; 0.25] & 1.1 \%\end{array}$

0.00 [0.00; 0.25$] \quad 1.1 \%$

$0.01[0.00 ; 0.01] \quad 2.1 \%$

0.03 [0.01: 0.07$] \quad 4.6 \%$

0.09 [0.04;0.16] $2.5 \%$

$0.12[0.04 ; 0.27] \quad 1.0 \%$

$\begin{array}{lll}0.00 & {[0.00 ; 0.07]} & 4.6 \% \\ 0.04 & 0.00 ; 0.14] & 2.6 \%\end{array}$

$\begin{array}{lll}0.04 & {[0.00 ; 0.14]} & 2.6 \% \\ 0.16 & {[0.07 ; 0.29]} & 1.0 \%\end{array}$

$\begin{array}{lll}0.16 \text { [0.07; } 0.29] & 1.0 \% \\ 0.00[0.00 ; 0.17] & 2.1 \%\end{array}$

0.08 [0.03; 0.19] $2.1 \%$

0.35 [0.15;0.59] $1.8 \%$

$0.3 \%$

$0.05[0.02: 0.08] \quad 4.3 \%$

0.23 [0.13;0.36] $1.0 \%$

0.33 [0.10;0.65] $0.2 \%$

$0.10[0.03 ; 0.21] \quad 1.5 \%$

$0.05[0.01: 0.14] \quad 2.5 \%$

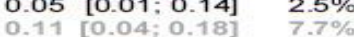

$\begin{array}{lll}0.04 & {[0.01 ; 0.15]} & 2.3 \% \\ 0.06 & {[0.01 ; 0.17]} & 2.0 \%\end{array}$

0.00 [0.00; 0.07 ] $4.6 \%$

$\begin{array}{ll}0.00 & 0.00 ; 0.07] \\ 0.03 \text { [0.00; } 0.06] & 8.6 \%\end{array}$

$0.03[0.02 ; 0.04] 100.0 \%$

Şekil 3. C. sakazakii prevalans çalışmalarına ait orman grafiği

Figure 3. Forest plot of the prevalence of $C$. sakazakii studies 
Tablo 1. Türkiye'de 2008-2019 ylları arasında C. sakazakii prevalansı ile ilgili yapılmış olan ve meta-analize dahil edilen çalışmaların özellikleri

Table 1. Characteristics of C. sakazakii prevalence studies included in the meta-analysis in Turkey between 20082019

\begin{tabular}{|c|c|c|c|c|}
\hline Çalışma & $\begin{array}{l}\text { Numune } \\
\text { sayisi }\end{array}$ & $\begin{array}{c}\text { Pozitif } \\
\text { numune } \\
\text { say1s1 }\end{array}$ & Prevalans & Gıda Türü \\
\hline Matyar ve ark. 2008 & 90 & 1 & 0.01 & Diğger \\
\hline Tokatlı 2009 & 62 & 3 & 0.05 & Bebek Maması \\
\hline Gökmen ve ark. 2010 & 160 & 5 & 0.03 & Süt ve Süt Ürünleri \\
\hline Güner ve ark. 2011 & 132 & 0 & 0 & Bebek Maması \\
\hline Karataş, 2011 & 100 & 9 & 0.09 & Süt ve Süt Ürünleri \\
\hline Menga, 2011 & 140 & 0 & 0 & Bebek Maması \\
\hline \multirow{2}{*}{ Polat Yemiş 2011} & 140 & 1 & 0.01 & Bebek Maması \\
\hline & 60 & 14 & 0.23 & Bebek Maması Hammaddeleri \\
\hline \multirow{2}{*}{ Dalkılıç Kaya 2011} & 55 & 2 & 0.04 & Bebek Maması \\
\hline & 40 & 5 & 0.13 & Süt ve Süt Ürünleri \\
\hline \multirow{3}{*}{ Koluman 2011} & 20 & 0 & 0 & Bebek Maması \\
\hline & 45 & 2 & 0.04 & Et ve Et Ürünleri \\
\hline & 40 & 1 & 0.03 & Diğer \\
\hline \multirow{2}{*}{ Çakmak 2012} & 350 & 4 & 0.01 & Bebek Maması \\
\hline & 50 & 0 & 0 & Süt ve Süt Ürünleri \\
\hline \multirow{2}{*}{ Abebe 2013} & 50 & 2 & 0.04 & Süt ve Süt Ürünleri \\
\hline & 50 & 3 & 0.06 & Et ve Et Ürünleri \\
\hline Cetinkaya ve ark. 2013 & 12 & 4 & 0.33 & Bebek Maması Hammaddeleri \\
\hline \multirow{2}{*}{ Çetingürbüz 2013} & 50 & 8 & 0.16 & Süt ve Süt Ürünleri \\
\hline & 20 & 1 & 0.05 & Bebek Maması \\
\hline Kimiran Erdem ve ark. 2013 & 50 & 13 & 0.26 & Diğger \\
\hline Sezer ve ark. 2015 & 50 & 0 & 0 & Bebek Maması \\
\hline Akgül Keser 2015 & 20 & 0 & 0 & Süt ve Süt Ürünleri \\
\hline \multirow{2}{*}{ Aksu ve ark. 2016} & 51 & 5 & 0.1 & Bebek Maması Hammaddeleri \\
\hline & 100 & 8 & 0.08 & Diğger \\
\hline \multirow{2}{*}{ Heperkan ve ark. 2017} & 59 & 5 & 0.08 & Süt ve Süt Ürünleri \\
\hline & 55 & 2 & 0.04 & Bebek Maması \\
\hline Cava Gümüş ve ark. 2017 & 60 & 3 & 0.05 & Bebek Maması Hammaddeleri \\
\hline Ozcakmak ve Cetinkaya. 2018 & 13 & 0 & 0 & Bebek Maması \\
\hline \multirow{4}{*}{ Demirci ve ark. 2018} & 20 & 0 & 0 & Bebek Maması \\
\hline & 60 & 3 & 0.05 & Bebek Maması Hammaddeleri \\
\hline & 20 & 7 & 0.35 & Süt ve Süt Ürünleri \\
\hline & 20 & 3 & 0.15 & Diğer \\
\hline \multirow{3}{*}{ Aksu ve ark. 2019} & 52 & 0 & 0 & Süt ve Süt Ürünleri \\
\hline & 50 & 0 & 0 & Et ve Et Ürünleri \\
\hline & 117 & 8 & 0.07 & Diğer \\
\hline Toplam & 2463 & 122 & 0.03 & \\
\hline
\end{tabular}

Bebek Mamas1; Yeni Doğan ve Devam Formülleri

Bebek Maması Hammaddeleri; İrmik, Pirinç Unu, Nişasta, Çavdar Unu, Yulaf Unu, Rezene

Et ve Et Ürünleri; Kıyma

Süt ve Süt Ürünleri; Süt, Süt Tozu, Peyniraltı Suyu Tozu, Peynir

Diğer; Marul, Çilek, Kırmızı Biber, Baharat/Otlar, Karides, Şekerleme, Tüketime Hazır Gıdalar, Hazır Çorba, Meyve ve

Sebzeler, Çevresel Toz 
Tablo 2. Gıda türlerine göre yapılan alt grup analizleri

Table 2. Subgroup analysis according to food types

\begin{tabular}{|c|c|c|c|c|c|c|c|c|c|}
\hline \multirow{2}{*}{$\begin{array}{l}\text { Değişkenler } \\
\text { Gıda Türleri }\end{array}$} & \multicolumn{6}{|c|}{ C. sakazakii Prevalansları } & \multicolumn{3}{|c|}{ Heterojenlik } \\
\hline & $\begin{array}{c}\text { Çalışma } \\
\text { sayısı }\end{array}$ & $\begin{array}{l}\text { Örnek } \\
\text { Sayısı }\end{array}$ & $\begin{array}{c}\text { Pozitif } \\
\text { örnek } \\
\text { sayısı }\end{array}$ & Prevalans & $\% 95$ GA & $\begin{array}{c}P \\
\text { Değeri }\end{array}$ & Cochrane's Q & $P^{2}(\%)$ & $\tau^{2}$ \\
\hline Bebek mamas1 & 12 & 1057 & 13 & 0.01 & $(0.00-0.01)$ & 0.54 & 9.92 & 0 & $<0.001$ \\
\hline $\begin{array}{l}\text { Bebek mamas } 1 \\
\text { hammaddeleri }\end{array}$ & 10 & 243 & 29 & 0.11 & $(0.04-0.18)$ & $<0.01$ & 13.81 & 71 & 0.004 \\
\hline Süt ve süt ürünleri & 5 & 601 & 41 & 0.05 & $(0.02-0.08)$ & $<0.01$ & 35.49 & 75 & 0.002 \\
\hline Et ve et ürünleri & 3 & 145 & 5 & 0.03 & $(0.00-0.06)$ & 0.14 & 3.89 & 49 & 0.001 \\
\hline
\end{tabular}

Cochrane's Q: Gözlenen etki büyüklüklerinin ağıllıklı kareler toplamı;

I \%: Gerçek varyansın gözlenen varyansa oranı;

$\tau^{2}$ : Gerçek etkilerdeki çalışmalar arası varyans;

GA: Güven Aralığ1

Tablo 3. Farklı gıda türlerinde gözlenen C. sakazaki prevalanslarının meta-regresyon analizleri

Table 3. Meta-regression analysis of the prevalence of C. sakazaki in food subgroups

\begin{tabular}{lcccccc}
\hline Gida Türleri & N & Katsayı & SH & $\begin{array}{c}\text { Z- } \\
\text { değeri }\end{array}$ & P Değeri & $\begin{array}{c}\text { İstatistik önem kontrolü } \\
\text { (Cochrane's Q) }\end{array}$ \\
\hline Sabit & 30 & 0.01 & 0.007 & 1.43 & 0.153 & $\mathrm{Q}=15.266$ \\
Bebek mamas1 (Referans) & 12 & 0.00 & - & - & - & $\mathrm{df}=3$ \\
Bebek mamas1 hammaddeleri & 10 & 0.07 & 0.021 & 3.66 & $<0.001$ & $I^{2}: 58.80$ \\
Süt ve süt ürünleri & 5 & 0.03 & 0.012 & 2.07 & 0.039 & $P=0.002$ \\
Et ve et ürünleri & 3 & 0.01 & 0.018 & 0.64 & 0.521 & \\
\hline
\end{tabular}

$\mathbf{N}$ : Çalışma sayısi; SH: Standart Hata; $\mathbf{R}^{2}$ Analog $=0.47$

\section{TARTIŞMA}

Meta-analiz, birbirinden bağımsız ve aynı etki büyüklüğünü ihtiva eden çalışmaların sonuçlarının birleștirilip yeniden yorumlanmasını hedefleyen bir yöntemidir. Bu yöntem, bazı dezavantajları olduğu düşünülmesine karşin popülasyon gerçek etki büyüklüğüne ilişkin daha güçlü ve kesin tahmin yapma ve bireysel çalışmalardaki tutarsızlıkların giderilmesi hususunda önemli bir yer edinmiştir. Meta-analizin kullanımı tıp, veteriner hekimlik, tarım ve eğitim gibi birçok alanda yaygınlaşmıştır. Metaanaliz çalışmaları daha çok sosyal bilimlerde yapılmakta ancak son zamanlarda sağlık bilimleri ve gıda güvenliği araştırmalarında da meta-analiz yapıldığ1 görülmektedir. Gida mikrobiyolojisi açısından meta-analiz oldukça güncel ve amaca yönelik bir metot olarak değerlendirilmekte ve farklı patojenler ile ilgili birçok çalışmaya rastlanmaktadır. Örneğin, Churchill ve ark. (2019), şarküteri eti, yumuşak peynir ve paketlenmiş salatadaki Listeria monocytogenes prevalansinı meta-analiz ile ortaya koymay1 amaçlamıştır. Assefa ve Bihon (2018), Etiyopya'da farklı hayvan kaynaklı gidalarda Eschericbia coli prevalans verilerini aynı metot ile bir araya getirmiştir. Gutema ve ark (2019), 2000-2017 y1lları arasında yayınlanan çalışmaların meta-analizini uygulayarak sağlıklı sığırlarda Salmonella’nın ortak prevalansını tahmin etmeyi ve serotip çeşitliliğini incelemeyi amaçlamışlardır.

Türkiye'de farklı bölgelerde, çeşitli gida tiplerinde Cronobacter ile ilgili prevalans çalışmaları bulunmaktadır. $\mathrm{Bu}$ çalışmada, Türkiye'de satışa sunulan gidalarda $C$. sakazakir nin ortak prevalans oranını belirlemek amaciyla mevcut birincil çalışmaların sonuçlarını nicel olarak birleştiren bir meta-analiz yapilarak ortak bir prevalans ortaya konulmuştur. C. sakazakii'ye ilişkin ortak prevalans değeri 0.03 (\%95 Güven aralı̆̆1; 0.02-0.04) olarak hesaplanmış olup istatistiksel olarak anlamlı olduğu belirlenmiştir $(\mathrm{p}<0.001)$. Buna karşın, Demirci ve ark (2018), C. sakazakii prevalansinı 0.35 belirlemişken; Çakmak (2012), incelediği hiçbir gıda numunesinde $C$. sakaz̧akii tespit etmemiştir. Bu şartlarda Türkiye'nin farklı bölgelerinde gerçekleştirilmiş olan bağımsız ve heterojen çalışma bulgularının istatstistiksel olarak bir araya getirilmesi ile C. sakazakii prevalansi ile ilgili ülke genelini yansıtan net bir veri elde edildiği düşünülmektedir.

Çalışma kapsamında gerçekleştirilen alt grup analizlerinde, en yüksek C. sakazakii prevalansı bebek maması hammaddelerinde (0.11), en düşük prevalans ise bebek mamasında bulunmuştur (0.01). Çalışmaya dahil edilmiş olan bebek mamasına ilişkin en yüksek C. sakazakii prevalans1 0.48 (Tokatl 2009) iken en düşük prevalans ise 0 olarak bulunmuştur. Bebek maması hammaddelerine ilişkin ise en yüksek prevalans 0.33 (Çetinkaya ve ark. 2013) olarak belirlenirken, en düşük prevalans ise 0.05 (Cava Gümüş ve ark. 2017, Demirci ve ark. 2018) olarak rapor edilmiştir. Sani ve Odeyemi (2015)'nin dünya genelinde Cronobacter spp. prevalans çalışmalarını bir araya getirdiği meta-analiz sonuçlarına göre, bitkisel kaynakl1 g1da maddelerinde prevalans oran1 0.201 (\%95 güven aralığ1 0.168-0.238) olup Cronobacter spp. varllğının hayvansal gidalara (0.08 (\%95 güven aralığ1 0.066-0.096)) oranla daha yaygin; heterojenlik açısından baharat ve sebze gibi bitkisel kaynaklı gida maddelerinin $\left(I^{2}=84\right)$, hayvansal gidalara oranla $\left(I^{2}\right.$ $=82$ ) daha yüksek olduğu rapor edilmiștir. Bitkisel 
kaynaklı g1daların Cronobacter spp.'ye rezervuar teşkil ederek kontaminasyon yolu oluşturduğu sonucuna ulaşılmıştır (Sani ve Odeyemi 2015). Bu çalışmada da bebek formüllerinde kullanılan bitkisel kaynaklı hammaddelerin (irmik, pirinç unu, nişasta), diğer gıda maddelerine oranla $C$. sakazakii açısından yüksek prevalans gösterdiği sonucuna varılmıştır. Bu durumda çalışma sonuçlarının, Sani ve Odeyemi'nin (2015) bulguları ile paralellik gösterdiği görülmektedir.

Prevalans çalışmalarından yola çıkılarak, besin içeriklerinin tozlaştırışmış, kurutulmuş ve düşük su aktivitelerine sahip olması özellikleri göz önünde bulundurulduğunda, C. sakazakii özellikle bebek formülü üretiminde dirençli bir g1da patojeni olduğu bilinmektedir. Enterobacteriacea ailesine ait olan ve düşük su aktivitesi seviyelerinde canlılığını uzun süre sürdüren C. sakazakii nin toz bebek mamalarında ve kuru bileşenlerde bulunma olasılığı yüksektir. Bu durum nedeniyle hassas grupta yer alan infantlar $C$. sakazakii açısından tehlike altındadir. Van acker ve ark. (2001) tarafından bildirilen 12 yenidoğan bebekte görülen süt bazlı toz bebek mamalarınından kaynaklandığ1 ortaya konmuş nekrotize enterokolitis ile karakterize C. sakazakii salgin1, patojenin ciddiyetini ortaya koymaktadır. Bu sebeple hammadde eldesinden itibaren gidanın tüketiciye sunulmasina kadar tüm g1da zincirinde g1da güvenliği uygun düzeyde tesis edilerek son üründe intrinsik ve ekstrinsik tüm kontaminasyon kaynakları elemine edilmelidir. Bu çalışma ile meta-analiz yönteminin gıda kaynaklı patojenlerin prevalanslarını belirlemede, böylece hastalık etkenlerinin elimine edilmesi için stratejilerin geliştirilmesinde ve yeni çalışma alanlarının belirlenmesinde etkili olabileceği düşünülmektedir. Bu çalışma ile Türkiye'de yapılmış C. Sakazaaki prevalansı ile ilgili elektronik ortamda yayınlanmış tüm çalışmalara ulaşılmaya çalışılmış ve ortak prevalans değeri hesaplanmıştır. Ancak Çalışma kapsamında sonuçların daha güvenilir olması açısından çok sayıda makaleye ulaşmalı ve bunun ulusal değerlendirme yanı sıra uluslararası analizlerin de yapılması gerekliliği ortaya çıkmıştır. Türkiye çapında yapılacak meta-analiz, risk analiz çalışmaları ve nöral network tabanlı makine öğrenmesi gibi yeni teknolojik analiz yöntemlerinin gida güvenliği ve öngörücü/tahminsel mikrobiyoloji alanlarında uygulanması gerekliliği halk sağlığ1 açısından önem arz etmektedir.

Çıkar Çatışması: Yazarlar, çıkar çatışması olmadı̆̆ını beyan eder.

\section{KAYNAKLAR}

Abebe GM. Çeşitli Gıda Örneklerinden İzole Edilen Enterobacter Sakazakii nin Biyofilm Olușumunun Araștırılması. Yüksek Lisans Tezi, Gazi Üniversitesi, Ankara, 2013.

Akgül Keser B. Çikolata ve Sütlü-Kremalı Keklerin Üretim Aşamalarında Potansiyel Risk Oluşturabilecek Listeria monocytogenes, Cronobacter (Enterobacter) sakazakii ve
Salmonella spp. Patojen Bakterilerinin Real-Time PCR Yöntemi ile Belirlenmesi. Yüksek Lisans Tezi, Ege Üniversitesi, İzmir, 2015.

Aksu F, Sandıkçı Altunatmaz S, Issa G, Özmen Togay S, Aksu H. Prevalence and identification by multiplex polymerase chain reaction patterns of Cronobacter spp. isolated from plant-based foods. Food Sci Technol. 2019; 36(4): 730-736.

Aksu F, Sandıkçı Altunatmaz S, Ossa G, Aksoy A, Aksu H. Prevalence of Cronobacter spp. in various foodstuffs and identification by multiplex PCR. Food Sci Technol. 2019; 39(3): 729-734

Anonim. CDC update: investigation of Cronobacter infections among infants in the United States. Centers for Disease Control and Prevention. 2011. http://www.cdc.gov/foodsafety/diseases/cronobacter/2 011-investigation/; 2011. Erişim tarihi: 07 Aralık 2019.

Anonim. Codex Alimentarius Commission. CAC/RCP 66-2008. Code of Hygienic Practice for Powdered Formulae for Infants and Young Children. 2008. www.fao.org/input/download/standards/11026/CXP_0 66e.pdf. Erişim Tarihi: 08 Aralık 2019.

Anonim. Commission Regulation (EC). Commission Regulation (EC) No 1441/2007 of 5 December 2007 amending Regulation (EC) No 2073/2005 on microbiological criteria for foodstuffs. 2007. https://eurlex.europa.eu/legalcontent/EN/TXT/PDF/?uri=CELEX:32007R1441\&fr om=EN. Erişim Tarihi: 08 Aralık 2019.

Anonim. FSANZ. Compendium of microbiological criteria for food.

2016. https://www.foodstandards.gov.au/publications/Docum ents/Compedium $\% 20$ of $\% 20$ Microbiological\%20Criteria/ Compendium $\% 20$ of $\% 20$ Microbiological $\% 20$ Criteria.pdf . Erişim Tarihi: 08 Aralık 2019.

Anonim. Türk Gida Kodeksi Mikrobiyolojik Kriterler Yönetmeliği 2011. 29 Aralık 2011 tarihli ve 28157 sayll Resmi Gazete. Erișim Tarihi: 19.01.2020.

Assefa A, Bihon A. A systematic review and metaanalysis of prevalence of Escherichia coli in foods of animal origin in Ethiopia. Heliyon. 2018; 4: e00716.

Cava Gümüş P, Tekiner İH, Çakmak B, Tacer Caba Z, Özpinar H. Investigation of Extended Spectrum BLactamases(ESBL)-Producing Enterobacteriaceae and Cronobacter spp. in Infant Formulas and Cereal-Based Foods for Children. IGUSABDER. 2017; 1: 19-32.

Churchill KJ, Jan M. Sargeant JM, Farber JM, O'connor AM. Prevalence of Listeria monocytogenes in Select Ready-to-Eat Foods-Deli Meat, Soft Cheese, and Packaged Salad: A Systematic Review and Meta-Analysis. J Food Prot. 2019; 82(2): 344-357.

Çakmak B. Piyasada Satışa Sunulan Çeșitli Bebek Mamalarında ve Pastörize Sütlerde Enterobacter Sakazakiìnin Varlığı. Doktora Tezi, İstanbul Üniversitesi, İstanbul, 2012.

Çetingürbüz B. Hazır Toz Bebek Mamaları ve Çiğ Sütlerde Enterobacter Sakazakï nin Bulunma Sıklığı. Yüksek Lisans Tezi, Gazi Üniversitesi, Ankara, 2013.

Çetinkaya E, Joseph S, Ayhan K, Forsythe SJ. Comparison of methods for the microbiological identification and profiling of Cronobacter species from ingredients used in the preparation of infant formula. Mol Cell Probes. 2013; 27: 60-64.

Dalkılıç Kaya G. Süt Ürünleri ve Bebek Mamalarında Enterobacter Sakaz̧akii (Cronobacter spp.) Varlığının Araştırılması ve Gelișmesinde Sicaklık ve Seker Çeșitlerinin Etkisi. 
Doktora Tezi, İstanbul Teknik Üniversitesi, İstanbul, 2011.

Demirci Ü, Tekiner İH, Cakmak B, Özpınar H. Occurrence and molecular characterization of different virulenceassociated genes of Cronobacter sakazakii isolates from some foods and dust samples. Cienc Rural. 2018; 48(8): e20180127.

Duval S, Tweedie R. Trim and fill: A simple funnel-plot-based method of testing and adjusting for publication bias in meta-analysis. Biometrics. 2000; 56(2): 455-63.

Friedermann M. Enterobacter sakazakii in food and beverages (other than infant formula and milk powder). Int J Food Microbiol. 2007; 1161-10.

Garbowska M, Berthold-Pluta A, Stasiak-Rozanska L. Microbiological quality of selected spices and herbs including the presence of Cronobacter spp. Food Microbiol. 2015; 49: 1-5.

Gökmen M, Tekinşen KK, Gürbüz Ü. Presence of Enterobacter Sakazakii in Milk Powder, Whey Powder and White Cheese Produced in Konya. Kafkas Univ Vet Fak Derg. 2010; 16: 163-166.

Gutema FD, Agga GE, Abdi RD, De Zutter L, Duchateau L, Gabriël S. Prevalence and Serotype Diversity of Salmonella in Apparently Healthy Cattle: Systematic Review and Meta-Analysis of Published Studies. 20002017 Front Vet Sci. 2019; 6: 102.

Güner A, Doğruer Y, Cebirbay MA, Yalçın S, Gülsen S, Telli $\mathbf{N}$. An investigation on the prevalence of Cronobacter sakazakii in powdered infant formula consumed in Turkey. J Food Agri Environ. 2011; 9(2): 82-84.

Heperkan D, Dalkilic-Kaya G, Juneja VK. Cronobacter sakazakii in baby foods and baby food ingredients of dairy origin and microbiological profile of positive samples. LWTFood Sci Technol. 2017; 75: 402-407.

Holy O, Forstythe S. Cronobacter spp. as emerging causes of healthcareassociated infection. J Hosp Infect. 2014; 86: $169-177$.

Hu S, Yu Y, Xiao X. Stress resistance, detection and disinfection of Cronobacter spp. in dairy products: A review. Food Control. 2018; 85: 400-415.

Iversen C, Mullane N, McCardell B, Tal BD, Lehner A, Fanning S, Stephan R, Joosten H. Cronobacter gen. nov., a new genus to accommodate the biogroups of Enterobacter sakazakii, and proposal of Cronobacter sakazakii gen. nov., comb. nov.,Cronobacter malonaticus sp. nov., Cronobacter turicensis sp. nov., Cronobacter muytjensii sp. nov., Cronobacter dublinensis sp. nov., Cronobacter genomospecies 1, and of three subspecies, Cronobacter dublinensis subsp. dublinensis subsp. nov., Cronobacter dublinensis subsp. lausannensis subsp. nov. and Cronobacter dublinensis subsp. lactaridi subsp. nov. Int J Syst Evol Microbiol. 2008; 58: 1442-1447.

Jaradat ZW, Al Mousa W, Elbetieha A, Al Nabulsi A, Tall BD. Cronobacter spp.-opportunistic food-borne pathogens. A review of their virulence and environmental-adaptive traits. J Med Microbiol. 2014; 63: 1023-1037.

Kalyantanda G, Shumyak L, Archibald LK. Cronobacter Species Contamination of Powdered Infant Formula and the Implications for Neonatal Health. Front Pediatr. 2015; 3: 56

Karataş M. Tunceli Bölgesinde Satışa Sunulan Geleneksel Şavak Tulum Peynirlerinin Cronobacter Spp. Yönünden İncelenmesi, 16s rRNA Dizi Analizi ile Alt Tür Belirlemesi ve Suşların Antibiyotik Dirençliliğinin
Saptanması. Yüksek Lisans Tezi, Tunceli Üniversitesi, Tunceli, 2014.

Kimiran-Erdem A, Arslan-Aydoğdu EÖ, Gürün S Bacteriological analysis of the red pepper spices marketed as packaged and unpackaged in Istanbul. IUFS J Biol. 2013; 72(2): 23-30.

Koluman A. Çeşitli Gıdalardan Cronobacter spp. (Enterobacter Sakazakii) İzolasyon ve İdentifikasyonu. GTED. 2011; 6(2): 16-19.

Kucerova E, Clifton SW, Xia XQ, Long F, Porwollik S, Fulton L, Fronick C, Minx P, Kyung K, Warren W, Fulton R, Feng D, Wollam A, Bhonagiri SNV, Nash WE, Hallsworth-Pepin K, Wilson RK, McClellandand M, Forsythe SJ. Genome sequence of Cronobacter sakazakii BAA-894 and comparative genomic hybridization analysis with other Cronobacter species. PLoS One. 2010; 5: e9556.

Li Y, Chen Q, Zhao J, Jiang H, Lu F, Bie X, Lu Z. Isolation, identification and antimicrobial resistance of Cronobacter spp. isolated from various foods in China. Food Control. 2014; 37: 109-114

Matyar F, Kaya A, Dinçer S. Antibacterial Agents and Heavy Metal Resistance in Gram-Negative Bacteria Isolated From Seawater, Shrimp And Sediment in Iskenderun Bay, Turkey. Science of The Total Environ. 2008; 407: 279-285.

Menga M. Toz Bebek Mamalarında ve Yeni Doğan Beslenme Tüplerinde Cronobacter spp. (Enterobacter Sakazakii) Araştırılması. Yüksek Lisans Tezi, İstanbul Üniversitesi, İstanbul, 2011

Özçakmak S, Çetïnkaya A. The presence of Cronobacter sakazakii, Enterobacteriaceae spp. and Ochratoxin-A in Infant Rice-based formula and milled rice products. Hitite J Sci Eng. 2018; 5(2): 85-90.

Patsopoulous N, Evangelou E., Ioannidis JPA. Sensitivity of between-study heterogeneity in metaanalysis: proposed metrics and empirical evaluation. Int J Epidemiol. 2008; 37(5): 1148-1157.

Polat Yemiş G. Cronobacter Sakazakii'nin Bebek Mamalarından İzolasyonu ve Gelișme Parametrelerinin İncelenmesi. Doktora Tezi, Ankara Üniversitesi, Ankara, 2011.

Sani NA, Odeyemi OA. Occurrence and prevalence of Cronobacter spp. in plant and animal derived food sources: a systematic review and meta-analysis. Springerplus. 2015; 4: 545 .

Sezer C, Vatansever L, Bilge N. The Microbiological Quality of Infant Milk and Follow-on Formula. Van Vet J. 2015; 26(1): 31-34.

Sutton AJ, Abrams KR, Jones DR. An illustrated guide to the methods of meta-analysis. J Eval Clin Pract. 2001; 7: 135148.

Tokatlı N. Farklı Formülasyonlarda Üretilen Bebek Mamalarının Bileşimi, Bazı Mikrobiyojik Özellikleri ve Enterobacter Sakazakii Varlığının Belirlenmesi. Yüksek Lisans Tezi, Namık Kemal Üniversitesi, Tekirdağ, 2009.

Van Acker J, de Smet F, Muyldermans G, Bougatef A, Naessens A, Lauwers $S$. Outbreak of necrotizing enterocolitis associated with Enterobacter sakazakii in powdered milk formula. J Clin Microbiol. 2001; 39(1): 293-297. 